\title{
ÁGUAS SUBTERRÂNEAS DE REGIÃO PRODUTORA DE CANA-DE-AÇÚCAR PAULISTA: RELAÇÃO ENTRE INDICADORES DE QUALIDADE E CARACTERÍSTICAS DO POÇO
}

LOPES, Laudicéia Giacometti ${ }^{1}$ PINTO, Fernanda de Rezende ${ }^{2}$ FERRAUDO, Antonio Sergio ${ }^{3}$ AMARAL, Luiz Augusto do ${ }^{4}$ HOJAIJ, Aparecido 5

Recebido em: 2009.12.16

Aprovado em: 2010.03.30

ISSUE DOI: $10.3738 / 1982.2278-327$

RESUMO: No Brasil, o aumento do consumo de águas subterrâneas tem gerado interesse a respeito da situação destas fontes e dos fatores que interferem na qualidade das mesmas. O objetivo deste trabalho foi avaliar a influência das características construtivas na qualidade de água de poços localizados nas áreas urbana e rural de Jaboticabal, SP. A pesquisa foi conduzida com aplicação de questionário para levantamento das características dos poços e análise de água para cor aparente, turbidez, $\mathrm{pH}$, nitrato, coliformes totais e fecais. A análise de correspondência múltipla associou poços profundos localizados na área urbana com concentração de nitrato e poços rasos localizados na área rural com maior número de amostras de turbidez e coliformes fecais fora dos padrões. Independentemente da localização do poço, o número de amostras de turbidez fora dos padrões apresentaram correspondência também com poços sem calçada e sem parede acima do solo. Assim, poços mal protegidos podem colaborar com o aporte de contaminantes para a água subterrânea.

Palavras-chave: Água potável, Água subterrânea, Nitrato.

\section{SUBTERRANEAN WATERS IN THE SÃO PAULO PRODUCTION REGION OF SUGAR CANE: THE RELATION BETWEEN THE INDICATORS OF QUALITY AND WATER-WELL CHARACTERISTICS}

\begin{abstract}
SUMMARY: To evaluate the influence of the constructive characteristics in well-water quality situated in the urban and rural areas of Jaboticabal - São Paulo, this study was conducted through the application of a questionnaire to discover the characteristics of wells and analyze the water for quality indicators. The analysis of multiple correspondence associated deep wells, situated in urban areas with a concentration of nitrate, and shallow wells, situated in rural areas, with a higher number of samples showing turbidity and thermotolerant coliforms above the limit of human potability. Thus badly protected wells can aid the transportation of contaminants to subterranean waters.
\end{abstract}

Keywords: Potable water. Groundwater. Nitrate.

\footnotetext{
${ }^{1}$ Serviço Autônomo de Água e Esgoto de Jaboticabal, Av. Jornalista Cláudio Luis Berchielli, 345, Jaboticabal - SP, laudiceia_lopes@globo.com.

${ }^{2}$ Doutoranda pelo Programa de Pós-Graduação em Medicina Veterinária (área de M.V. Preventiva) pela

Universidade Estadual Paulista Júlio de Mesquita Filho

${ }^{3}$ Prof. Dr. em Agronomia (Energia na Agricultura) pela Universidade Estadual Paulista Júlio de Mesquita Filho. Licenciatura em Matemática.

${ }^{4}$ Prof. Dr. Medicina Veterinária-Saúde Pública. Estadual Paulista Júlio de Mesquita Filho.

${ }^{5}$ Coordenador da Câmara Técnica de Gestão e Planejamento do CBH/Mogi, representante do segmento município e ASSEMAE
} 


\section{INTRODUÇÃO}

No interior do Estado de São Paulo, o aumento da demanda por água potável devido ao crescimento populacional deve ser atendido principalmente por águas subterrâneas, uma vez que a ampliação do volume de águas superficiais captado não poderá ser viabilizada por questões quali ou quantitativas. Sendo assim, o levantamento da qualidade das águas subterrâneas e o entendimento dos fatores que governam os processos de degradação, tornamse estratégicos para o desenvolvimento socioeconômico.

Entre as regiões do Brasil cujas águas subterrâneas urbanas foram avaliadas, está o município de Belo Horizonte - MG (BEATO et al., 2003), onde foram cadastrados 147 poços e, em parte desses, cujas águas foram analisadas, 9,2\% dos resultados estavam fora dos padrões de potabilidade descritos na legislação (BRASIL, 2004). A falta de infraestrutura de saneamento (disposição inadequada de resíduos sólidos e esgoto) foi apontada pelos autores como a principal fonte de contaminação. A disposição inadequada de esgoto também foi a principal causa de depreciação da qualidade de águas subterrâneas no Parque Ecológico do Tietê, São Paulo - SP (VARNIER ; HIRATA, 2002).

$\mathrm{Na}$ área rural, a presença de resíduos animais, de fossas sépticas ou fossas negras e de fertilizantes inorgânicos e orgânicos é considerada como o principal fator de risco, e a extensão dos danos causados depende das práticas agrícolas adotadas (WASSENAAR; HENDRY; HARRINGTON, 2006). Em área produtora de cana-de-açúcar, a vinhaça (resíduo da produção de álcool, que possui elevadas concentrações de nitrato, de potássio e de matéria orgânica) é usualmente aplicada no solo, e dependendo da dose aplicada e do tipo de solo, pode oferecer risco às águas subterrâneas (SILVA; GRIEBELER; BORGES, 2007).

Além da proximidade de fontes de poluição, a ausência de fatores de proteção nos poços pode colaborar com a entrada de contaminantes. A localização das fontes de água subterrânea no ponto mais alto do terreno, a construção de parede acima do solo, a impermeabilização interna e a presença de tampa são medidas importantes para prevenir a contaminação da água e são considerados fatores de proteção (AMARAL, 1996).

Poços mal protegidos podem levar à poluição do aquífero, provocando a degradação de bem estratégico. Na região centro-oeste dos Estados Unidos, os poços mais rasos, antigos e localizados próximos à área agrícola com solo arenoso foram encontrados como sendo os mais vulneráveis (RICHARDS et al., 1996).

O nitrato, embora presente naturalmente em concentrações moderadas em águas subterrâneas, é frequentemente enriquecido a níveis contaminantes pelo contato com percolado de fertilizantes, sistemas sépticos ou resíduos animais (BROOKS ; CECH, 1979). 
A presença de nitrato em água de consumo humano oferece risco, uma vez que o mesmo tem sido considerado carcinogênico, além de causador de metaemoglobinemia e de abortos espontâneos (CALDERON, 2000). Sendo assim, o nitrato consiste em indicador de qualidade de águas subterrâneas e, juntamente com outros parâmetros não específicos (turbidez, cor aparente, $\mathrm{pH}$ ) e microbiológicos (coliformes totais e termotolerantes), pode oferecer informações sobre a condição da água e a influência do entorno do poço.

Diante disso, o objetivo deste trabalho foi avaliar a qualidade da água subterrânea, em poços das áreas urbana e rural no município de Jaboticabal - SP, quanto à presença de características construtivas protetoras, utilizando análise de correspondência múltipla.

\section{MÉTODOS}

Entre junho e agosto de 2008, considerado período de seca, foram coletadas 16 amostras de água de poços particulares localizados na área urbana e 23 amostras na área rural, pertencentes ao município de Jaboticabal, situado entre as coordenadas $21^{\circ} 10^{\prime}$ e $21^{\circ} 27^{\prime} \mathrm{S}$, e $48^{\circ} 08^{\prime}$ e $48^{\circ} 33^{\prime}$ W, região administrativa de Ribeirão Preto, porção centro-norte do Estado de São Paulo.

O município possui aproximadamente 73.643 habitantes e é atendido em 99,98\% da extensão urbana pela rede pública de água e 99,27\% pela coleta de esgoto (SEADE, 2009). O clima é do tipo Aw, segundo classificação de Köeppen, com período das chuvas entre outubro e março, e seca de abril a setembro (JABOTICABAL, 2007). Os tipos de solos predominantes no município são Latossolo Vermelho-Escuro de fase arenosa (31.860 ha), representando 47\% do território, e Latossolo Roxo (25.330 ha), 37\% do território (JABOTICABAL, 2007). A área rural é ocupada principalmente com pastagem (9\%) e com a cultura de cana-de-açúcar (73\%) (LOPES et al., 2008). A prevalência da última ocorre desde o início da década de 1980, em função dos incentivos governamentais para a produção de álcool etílico combustível.

As características construtivas dos poços amostrados foram: presença de tampa, calçada ao redor, revestimento interno, parede acima do solo e profundidade maior que $20 \mathrm{~m}$. O levantamento desses dados foi conduzido por meio da aplicação de questionário.

As amostras de água dos poços foram coletadas de acordo com procedimentos-padrão (AMERICAN PUBLIC HEALTH ASSOCIATION, 1992) e, em seguida, encaminhadas para o Laboratório do Serviço Autônomo de Água e Esgoto de Jaboticabal, onde foram analisados os parâmetros indicadores de qualidade de água: cor aparente, turbidez, $\mathrm{pH}$, nitrato, coliformes totais e coliformes termotolerantes. Esses parâmetros são definidos na Portaria MS 518 (BRASIL, 2004), e os critérios estabelecidos (Valores Máximos 
Permitidos, VMPs) pela mesma para a classificação da água potável são: turbidez, 1 NTU (Unidade Nefelométrica de Turbidez); cor aparente, $15 \mathrm{uH}$ (unidade Hazen); pH, entre 6 e 9,5; nitrato, $10 \mathrm{mg} \mathrm{N}-\mathrm{NO}_{3} \mathrm{~L}^{-1}$; coliformes totais, presença tolerada, desde que haja ausência de coliformes termotolerantes, e coliformes termotolerantes, ausência.

A cor aparente foi determinada de acordo com o método colorimétrico em espectrofotômetro DR 2000 Hach (HACH, 2008), e turbidez, de acordo com o método turbidimétrico $(\mathrm{HACH}, 1996)$, em turbidímetro 2100P Hach. O pH foi determinado em pHmetro 310 Orion e nitrato, de acordo com o método de redução por cádmio (HACH, 1996), em espectrofotômetro DR 2000 Hach. Os coliformes totais e os coliformes termotolerantes foram analisados pela utilização de método do substrato cromogênico (AMERICAN PUBLIC HEALTH ASSOCIATION, 1992).

A busca por possíveis correspondências envolvendo qualidade de água subterrânea, localização dos poços (rural e urbana) e características construtivas protetoras foi feita por análise de correspondência múltipla, que é considerada uma técnica exploratória de dados. Para a realização dessa, foi utilizada a tabela de Burt X’X, em que X é a matriz contendo os resultados dos parâmetros de qualidade de água e características construtivas levantadas (Tabela 3) (HAIR et. al., 2005). As análises foram processadas no software STATISTICA, versão 7.0 (STATSOFT, 2004). Os resultados da análise de correspondência múltipla foram apresentados no formato de mapa perceptivo.

Para a análise, foram excluídas as características tampa e revestimento interno por não apresentarem variabilidade nos resultados. Foi feita, também, uma seleção entre os parâmetros de qualidade, sendo escolhidos os que apresentam maior significado ambiental e sanitário (turbidez, nitrato e coliformes termotolerantes).

As características dos poços e a localização foram subdivididas em: com profundidade maior que 20 m (C_Prof), sem profundidade maior que $20 \mathrm{~m}$ (S_Prof), com parede acima do solo (C_ParA), sem parede acima do solo (S_ParA), com calçada ao redor (C_Cal), sem calçada ao redor (S_Cal), rural e urbano.

Para a qualidade de água, as subdivisões dos parâmetros de qualidade foram: resultados de turbidez dentro da legislação (Turb_D), turbidez fora da legislação (Turb_F), coliformes termotolerantes dentro da legislação (CT_D), coliformes termotolerantes fora da legislação (CT_F), nitrato menor que $3 \mathrm{mg} \mathrm{N}-\mathrm{NO}_{3} \mathrm{~L}^{-1}\left(\mathrm{NO}_{3}<3\right)$ e nitrato maior que $3 \mathrm{mg}$ N$\mathrm{NO}_{3} \mathrm{~L}^{-1}\left(\mathrm{NO}_{3}>3\right)$.

Para o nitrato, a categorização foi feita de acordo com o conceito preconizado por Squillace et al.(2002), utilizando a concentração de $3 \mathrm{mg} \mathrm{N} \mathrm{NO}_{3} \mathrm{~L}^{-1}$ para indicação de influência antropogênica e predição de suscetibilidade e vulnerabilidade do aquífero. A 
concentração de $10 \mathrm{mg} \mathrm{N}-\mathrm{NO}_{3} \mathrm{~L}^{-1}$, valor máximo permitido pela legislação (BRASIL, 2004), seria utilizada como segunda categoria, no entanto nenhuma amostra coletada para este estudo apresentou resultados acima desse patamar.

\section{RESULTADOS E DISCUSSÃO}

As médias dos resultados obtidos nas análises físico-químicas e microbiológicas de amostras de poços localizados na área urbana e na área rural estão apresentadas na Tabela 1.

Tabela 1. Média dos parâmetros de qualidade físico-química e microbiológica da água (média) de poços localizados na área rural e urbana do município de Jaboticabal - SP.

\begin{tabular}{|c|c|c|c|}
\hline \multirow{2}{*}{ Parâmetro } & \multirow{2}{*}{ Unidade } & \multicolumn{2}{|c|}{ Origem } \\
\hline & & Rural & Urbano \\
\hline $\mathrm{pH}$ & & 6,1 & 6,2 \\
\hline Turbidez & NTU* & 2,11 & 0,47 \\
\hline Cor aparente & $\mathrm{uH}^{*}$ & 5 & 2 \\
\hline Nitrato & $\mathrm{Mg} \mathrm{N}-\mathrm{NO}_{3} \mathrm{~L}^{-1}$ & 1,0 & 2,0 \\
\hline Coliformes totais & NMP $100 \mathrm{~mL}^{-1^{*}}$ & 337 & 22 \\
\hline Coliformes fecais & NMP $100 \mathrm{~mL}^{-1}$ & 4 & 7 \\
\hline
\end{tabular}

* NTU: unidade nefelométrica de turbidez. uH: unidade Hazen. NMP $100 \mathrm{~mL}^{-1}$, número mais provável por $100 \mathrm{~mL}$.

As médias de poços da área rural evidenciaram maior turbidez, cor aparente e coliformes totais (2,11 NTU; 5 uH e $\left.337 \mathrm{NMP} 100 \mathrm{~mL}^{-1}\right)$, comparadas com amostras da área urbana (0,47 NTU; 2 uH e 22 NMP $\left.100 \mathrm{~mL}^{-1}\right)$. Para a área urbana, as médias foram maiores para nitrato e coliformes termotolerantes $\left(2 \mathrm{mg} \mathrm{N}-\mathrm{NO}_{3} \mathrm{~L}^{-1}\right.$ e $\left.7 \mathrm{NMP} 100 \mathrm{~mL}^{-1}\right)$, comparadas à área rural (1,0 mg N-NO $3 \mathrm{~L}^{-1}$ e 4 NMP $\left.100 \mathrm{~mL}^{-1}\right)$.

Os resultados obtidos nas amostras dos poços da área urbana, em Jaboticabal, indicam superioridade da qualidade da água, comparados com os resultados descritos na literatura para áreas urbanas de regiões metropolitanas brasileiras, como Belo Horizonte e Natal (LUCENA; ROSA FILHO; BITTENCOURT, 2004). Na Tabela 2, com exceção do pH, os parâmetros para as regiões metropolitanas superam os de Jaboticabal, o que sugere a influência da infraestrutura urbana sob a qualidade de águas subterrâneas. 
Tabela 2. Resultados de parâmetros de qualidade de água obtidos para Jaboticabal - SP, e de estudos descritos na literatura.

\begin{tabular}{|c|c|c|c|}
\hline \multirow{2}{*}{ Parâmetro } & \multirow{2}{*}{ Jaboticabal } & \multicolumn{2}{|c|}{ Outros Estudos } \\
\hline & & Resultados & Local \\
\hline \multicolumn{4}{|l|}{$\overline{p H}$} \\
\hline \multirow{2}{*}{ Urbano } & $5,1-7,6$ & $5,35-7,15$ & Belo Horizonte \\
\hline & & $5.5-7.6$ & $\begin{array}{c}\text { (BEATO et al., 2003) } \\
\text { Natal (LUCENA et al., 2004) }\end{array}$ \\
\hline Rural & $5,0-8,1$ & $6,8-7,6$ & $\begin{array}{c}\text { Marondera, Zimbábue } \\
\text { (DZWAIRO et al., 2006) }\end{array}$ \\
\hline \multicolumn{4}{|l|}{ Turbidez (NTU) } \\
\hline \multirow{2}{*}{ Urbano } & $0,08-1,70$ & & $\begin{array}{l}\text { Belo Horizonte } \\
\text { (BEATO et }\end{array}$ \\
\hline & & $0->200$ & Natal (LUCENA et al., 2004) \\
\hline Rural & $0,16-20,2$ & $2-36$ & $\begin{array}{c}\text { Marondera, Zimbábue } \\
\text { (DZWAIRO et al., 2006) }\end{array}$ \\
\hline \multicolumn{4}{|l|}{ Cor aparente $(\mathrm{uH})$} \\
\hline Urbano & $1-5$ & $0->100$ & Natal (LUCENA et al., 2004) \\
\hline Rural & $1-41$ & & \\
\hline \multicolumn{4}{|l|}{$\begin{array}{l}\text { Nitrato } \\
\left(\mathrm{Mg} \mathrm{N}-\mathrm{NO}_{3} \mathrm{~L}^{-1}\right)\end{array}$} \\
\hline \multirow[t]{2}{*}{ Urbano } & $0,1-5,0$ & & $\begin{array}{c}\text { Belo Horizonte } \\
\text { (BEATO et al., 2003) }\end{array}$ \\
\hline & & $0-6,19$ & Natal (LUCENA et al., 2004) \\
\hline \multirow[t]{5}{*}{ Rural } & $0,0-3,1$ & $0-3,9$ & $\begin{array}{c}\text { Marondera, Zimbábue } \\
\text { (DZW AIRO et al., 2006) }\end{array}$ \\
\hline & & $0-45$ & $\begin{array}{c}\text { Califórnia, EUA } \\
\text { (WILLIAMS et al., 1998) }\end{array}$ \\
\hline & & $0,1-118$ & $\begin{array}{c}\text { Alabama, EUA } \\
\text { (LIU et al., 2005) }\end{array}$ \\
\hline & & $0,0-25,3$ & $\begin{array}{c}\text { Washington, EUA } \\
\text { (MITCHELL et al., 2003) }\end{array}$ \\
\hline & & $<0,1-100$ & $\begin{array}{c}\text { Iowa, EUA } \\
\text { (KROSS et al., 1993) }\end{array}$ \\
\hline
\end{tabular}

\section{Coliformes totais}

(NMP $100 \mathrm{~mL}^{-1}$ )

\begin{tabular}{lccc}
$\begin{array}{l}\text { Urbano } \\
\text { Rural }\end{array}$ & $0-201,4$ & $<2-2.400$ & $\begin{array}{c}\text { Belo Horizonte } \\
\text { (BEATO et al., 2003) }\end{array}$ \\
\hline $\begin{array}{l}\text { Coliformes } \\
\text { termotolerantes } \\
\text { (NMP 100 } \mathrm{mL}^{-1} \text { ) }\end{array}$ & $0-3.100$ & $58-1.900$ & $\begin{array}{c}\text { Marondera, Zimbábue } \\
\text { (DZWAIRO et al., 2006) }\end{array}$ \\
$\begin{array}{l}\text { Urbano } \\
\text { Rural }\end{array}$ & $0-114,5$ & $<2-2.400$ & $\begin{array}{c}\text { Belo Horizonte } \\
\text { (BEATO et al., 2003) }\end{array}$ \\
\hline & $0-22$ & $2-820$ & $\begin{array}{c}\text { Marondera, Zimbábue } \\
\text { (DZWAIRO et al., 2006) }\end{array}$ \\
\hline
\end{tabular}

$\mathrm{Na}$ área rural, para Jaboticabal, os resultados obtidos para os parâmetros nitrato e turbidez são concordantes com os resultados obtidos no distrito de Marondera, Zimbábue. Quanto aos coliformes totais, a variação esteve entre 0 e $3.100 \mathrm{NMP} 100 \mathrm{~mL}^{-1}$, sendo superior à encontrada em Zimbábue, entre 58 e $1.900 \mathrm{NMP} 100 \mathrm{~mL}^{-1}$; no entanto, a variação na 
contaminação fecal em Zimbábue (2 a 820 NMP $100 \mathrm{~mL}^{-1}$ ) foi superior à variação obtida em Jaboticabal (0 a 22 NMP $100 \mathrm{~mL}^{-1}$ ) (DZWAIRO et al., 2006).

Verificam-se, também, em Jaboticabal, melhores resultados na concentração de nitrato em poços da área rural, comparados com os descritos para algumas regiões da Califórnia (WILLIAMS et al., 1998), do Alabama (LIU; MING; ANKUMAH, 2005), de Washington (MITCHELL et al., 2003) e de Iowa (KROSS et al., 1993).

A porcentagem de amostras fora dos padrões de potabilidade humana estabelecidos na Portaria 518/04 (BRASIL, 2004²), para as duas áreas estudadas em Jaboticabal, é apresentada na Figura 1.

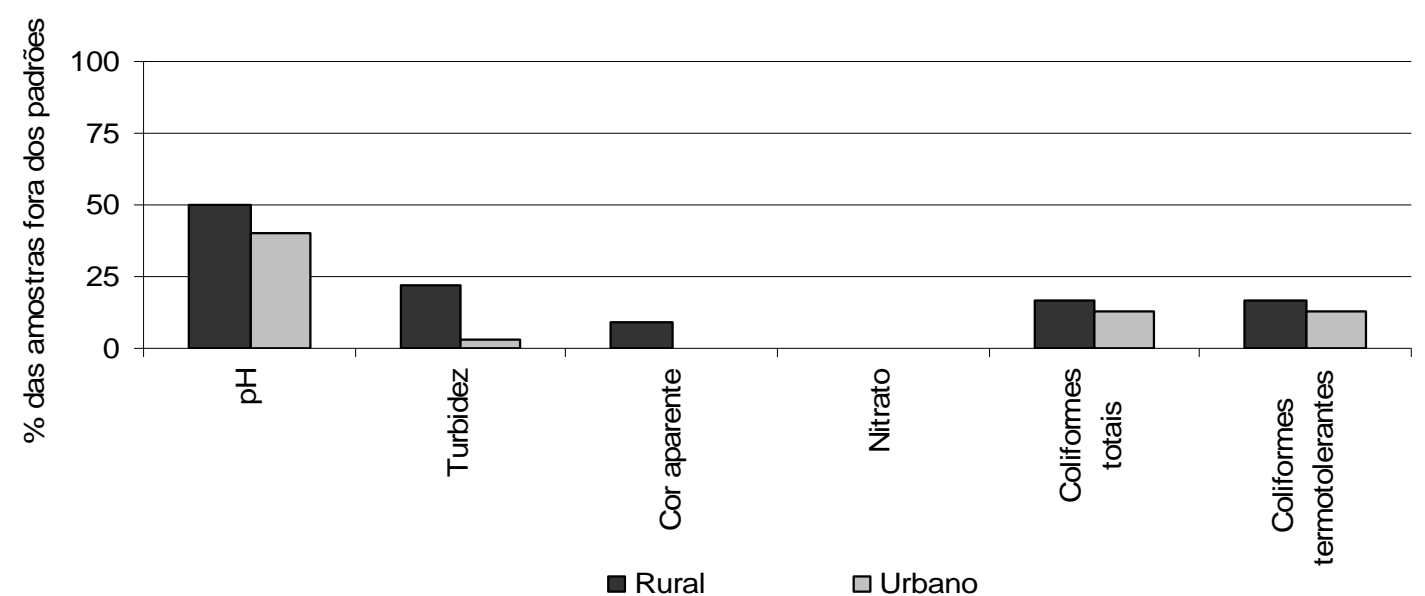

Figura 1. Porcentagem das amostras de água de poços das áreas urbana e rural de Jaboticabal - SP, fora do padrão de potabilidade.

$\mathrm{Na}$ área rural, a superioridade das frequências de amostras fora dos padrões acontece em todos os parâmetros, indicando maior risco no consumo humano ou animal de água dessas fontes. Quanto ao nitrato, $40 \%$ das amostras analisadas em comunidades rurais da Califórnia (WILLIAMS et al., 1998), 1,7\% em Alabama (LIU; MING; ANKUMAH, 2005), 46\% em Washington (MITCHELL et al., 2003) e 18,3\% em Iowa (KROSS et al., 1993) apresentaram resultados fora dos padrões para nitrato, enquanto, em Jaboticabal, nenhuma amostra de nitrato ficou fora do padrão. Também, 9\% das amostras da área rural e 31\% das amostras da área urbana apresentaram concentração de nitrato acima de $3 \mathrm{mg} \mathrm{N} \mathrm{NO} \mathrm{L}^{-1}$. $\mathrm{Na}$ área rural de Washington, $65 \%$ dos poços apresentaram resultados acima de $3 \mathrm{mg} \mathrm{N}-\mathrm{NO}_{3} \mathrm{~L}^{-1}$ (MITCHELL et al., 2003).

Em Jaboticabal, $17 \%$ das amostras da área rural estavam fora dos padrões para coliformes totais, ou seja, apresentavam, além de coliformes totais, também coliformes termotolerantes. No entanto, a presença de coliformes totais foi constatada em $83 \%$ da área rural, contra 27\% para poços da área rural de Iowa, EUA (KROSS et al., 1993). 
Na Figura 2, apresenta-se o levantamento das características construtivas protetoras dos poços amostrados.

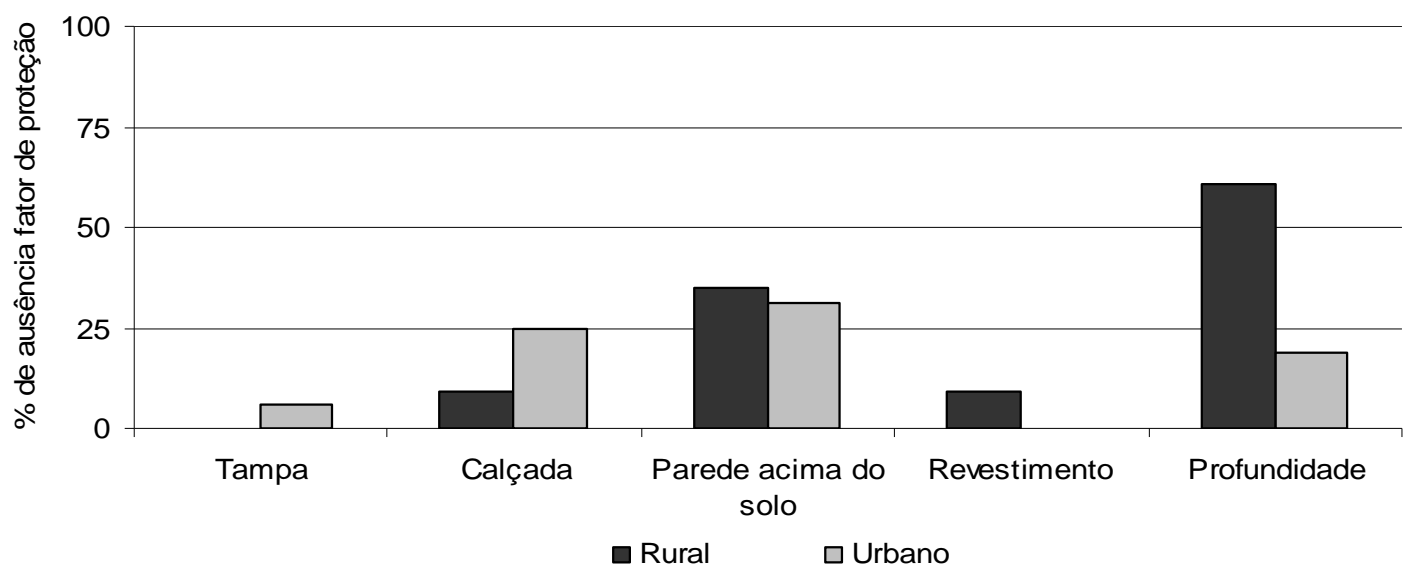

Figura 2. Porcentagem de poços com ausência das características construtivas protetoras.

A tampa e a calçada ao redor são características cuja ausência prevalece em poços da área urbana, e a parede acima do solo, o revestimento e a profundidade maior que $20 \mathrm{~m}$ estão ausentes com maior frequência em poços da área rural.

A associação entre a qualidade da água nas áreas urbana e rural de Jaboticabal e a ausência das características construtivas foi explorada pela análise de correspondência múltipla, que utilizou a tabela de Burt descrita na Tabela 3.

Tabela 3. Tabela de Burt para parâmetros de qualidade de águas subterrâneas e características construtivas de poços das áreas urbana e rural do município de Jaboticabal.

\begin{tabular}{lcccccccccccccc}
\hline \multicolumn{1}{c}{ Turb_D Turb_F } & NO3<3 & NO3 $>3$ & CF_D CF_FC_Cal S_Cal C_ParA S_ParAC_Prof S_Prof Urbano Rural \\
\hline Turb_D & $\mathbf{3 3}$ & 0 & 28 & 5 & 27 & 6 & 23 & 10 & 22 & 11 & 19 & 14 & 15 & 18 \\
Turb_F & 0 & $\mathbf{6}$ & 4 & 2 & 6 & 0 & 3 & 3 & 4 & 2 & 3 & 3 & 1 & 5 \\
NO3<3 & 28 & 4 & $\mathbf{3 2}$ & 0 & 27 & 5 & 21 & 11 & 21 & 11 & 17 & 15 & 11 & 21 \\
NO3>3 & 5 & 2 & 0 & $\mathbf{7}$ & 6 & 1 & 5 & 2 & 5 & 2 & 5 & 2 & 5 & 2 \\
CF_D & 27 & 6 & 27 & 6 & $\mathbf{3 3}$ & 0 & 22 & 11 & 21 & 12 & 19 & 14 & 14 & 19 \\
CF_F & 6 & 0 & 5 & 1 & 0 & $\mathbf{6}$ & 4 & 2 & 5 & 1 & 3 & 3 & 2 & 4 \\
C_Cal & 23 & 3 & 21 & 5 & 22 & 4 & $\mathbf{2 6}$ & 0 & 20 & 6 & 14 & 12 & 12 & 14 \\
S_Cal & 10 & 3 & 11 & 2 & 11 & 2 & 0 & $\mathbf{1 3}$ & 6 & 7 & 8 & 5 & 4 & 9 \\
C_ParA & 22 & 4 & 21 & 5 & 21 & 5 & 20 & 6 & $\mathbf{2 6}$ & 0 & 13 & 13 & 11 & 15 \\
S_ParA & 11 & 2 & 11 & 2 & 12 & 1 & 6 & 7 & 0 & $\mathbf{1 3}$ & 9 & 4 & 5 & 8 \\
C_Prof & 19 & 3 & 17 & 5 & 19 & 3 & 14 & 8 & 13 & 9 & $\mathbf{2 2}$ & 0 & 13 & 9 \\
S_Prof & 14 & 3 & 15 & 2 & 14 & 3 & 12 & 5 & 13 & 4 & 0 & $\mathbf{1 7}$ & 3 & 14 \\
Urbano & 15 & 1 & 11 & 5 & 14 & 2 & 12 & 4 & 11 & 5 & 13 & 3 & $\mathbf{1 6}$ & 0 \\
Rural & 18 & 5 & 21 & 2 & 19 & 4 & 14 & 9 & 15 & 8 & 9 & 14 & 0 & $\mathbf{2 3}$ \\
\hline
\end{tabular}


O mapa perceptivo (Figura 3), resultante da análise de correspondência múltipla, apresentou $44,05 \%$ da inércia original (23,13\% na dimensão 1 e 20,92\% na dimensão 2$)$.

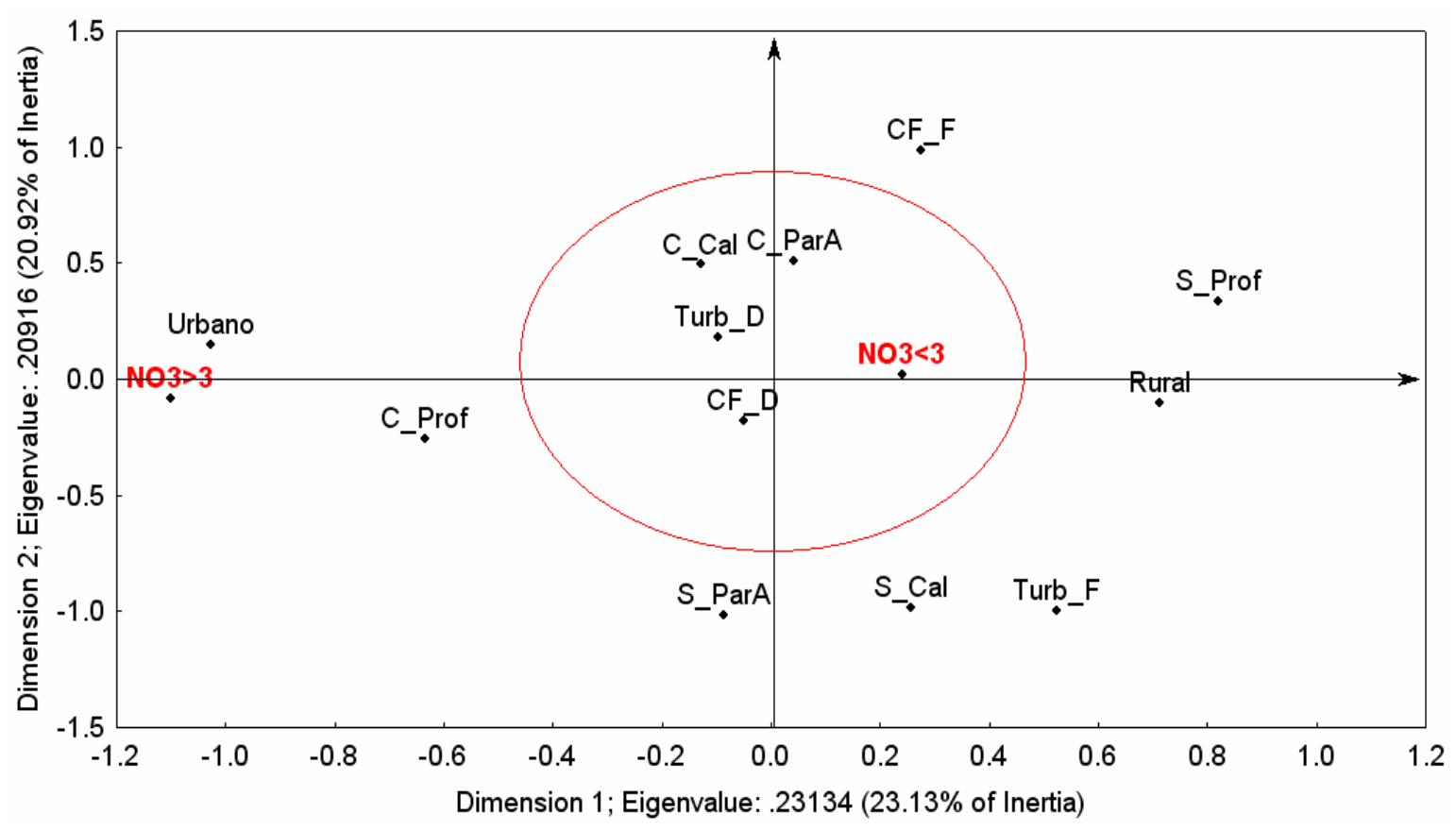

Figura 3. Mapa perceptivo resultante da análise de correspondência múltipla.

Os quatro grupos de correspondência encontrados estão destacados na Figura 3 e sugerem importantes tendências que ocorrem na região. Primeiramente, amostras com nitrato acima de $3 \mathrm{mg} \mathrm{N}-\mathrm{NO}_{3} \mathrm{~L}^{-1}$ estão associadas à área urbana e a poços com maior profundidade.

Esses resultados indicam que o uso de fertilizantes químicos na agricultura, a disposição de resíduos de produção de cana-de-açúcar, assim como a dispersão de resíduos animais exercem menor influência na qualidade da água subterrânea para o nitrato, do que os riscos presentes na área urbana. Outro aspecto importante consiste no fato de que, para a área urbana, os poços com maior profundidade apresentaram as maiores concentrações de nitrato. Essa associação pode indicar a incidência de contaminação remota que foi suspensa, como, por exemplo, contaminação por fossas sépticas ou negras em períodos do século $\mathrm{XX}$, onde a rede coletora de esgoto tinha abrangência menor que a atual de 99,27\% (SEADE, 2009).

No agrupamento central da Figura 3, também foi observada correspondência, ou seja, poços com calçada ao redor e com parede acima do solo apresentam resultados de turbidez e coliformes termotolerantes dentro dos padrões de potabilidade, assim como concentrações de nitrato menores que $3 \mathrm{Mg} \mathrm{N}-\mathrm{NO}_{3} \mathrm{~L}^{-1}$.

Para Jaboticabal, independentemente da localização do poço, os resultados de turbidez fora dos padrões estão associados a poços sem calçada e sem parede acima do solo (Figura 3). 
Poços rasos, localizados na área rural, têm correspondência discreta com turbidez e com coliformes termotolerantes fora dos padrões ( Figura 3 ). Essas correspondências indicam que poços rasos, sem calçada ao redor e sem parede acima do solo podem colaborar com o aporte de contaminantes para os reservatórios subterrâneos de água, conforme indicado pelos parâmetros turbidez e coliformes termotolerantes. Esse fato tem importantes implicações sanitárias, pois comprova o risco que esse tipo de abastecimento oferece para o consumo humano, assim como ambientais, pois sugere a degradação de recursos hídricos que deverão suprir a demanda de água no futuro.

\section{CONCLUSÃO}

Para o período estudado, os poços rasos da área rural apresentaram maior número de amostras fora dos padrões, devido à presença de contaminação de origem fecal (coliformes termotolerantes). As ausências de calçada ao redor e de parede acima do solo estão associadas ao aumento da turbidez. Sendo assim, a melhoria da construção dos poços poderia trazer benefícios em longo prazo para a preservação da qualidade da água subterrânea. Adicionalmente, embora não tenha excedido o padrão de potabilidade, a concentração de nitrato é maior em poços profundos localizados na área urbana, sugerindo impactos remotos suspensos.

\section{AGRADECIMENTOS}

À Fapesp, pelo financiamento da pesquisa referente à área rural, e ao SAAEJ, pelo apoio à pesquisa realizada na área urbana.

\section{REFERÊNCIAS}

AMARAL, L.A. Controle de qualidade da água utilizada em avicultura. In: MACARI, M. (Ed.) Água na avicultura industrial. Jaboticabal: FUNEP, 1996. p.93-124.

AMERICAN PUBLIC HEALTH ASSOCIATION. Standard methods for the examination of water and wastewater.16. ed. New York: APHA, 1992.

BEATO, D. A. C. et al. Impactos urbanos em águas subterrâneas - bacia da Lagoa da Pampulha, Belo Horizonte- MG. Revista Águas Subterrâneas, v. 17, p. 49-68, 2003.

BRASIL. Ministério da Saúde. Portaria 518, de 25 de Março de 2004.

BROOKS, D.; CECH, I.; Nitrates and bacterial distribution in rural domestic water supplies. Water Research, v. 13, p. 33-41, 1979. 
CALDERON, R. L. The epidemiology of chemical contaminants of drinking water. Food and chemical toxicology, v. 38, p. S13-S20, 2000.

DZWAIRO, B. et al. Assessment of the impacts of pit latrines on groundwater quality in rural áreas: a case study from marondera district, Zimbabwe. Physics and Chemistry of the Earth, v. 31, p. 779-788, 2006.

HACH COMPANY MANUAL. Dr/2000 Spectrophotometer instrument manual for use software version 3. Loveland, 1996. 58 p.

$\mathrm{HACH}$. Portable turbidimeter model 2100P instrument and procedure manual. 9.ed. Hach Company: China, 2008. 78 p.

HAIR JR, J.F. et al. Análise multivariada de dados. 5.ed. Porto Alegre: Bookman, 2005. $593 \mathrm{p}$.

JABOTICABAL. Cidade: geografia. Disponível em: 〈http://www.jaboticabal.com.br $>$. Acesso em: 3 mar. 2007.

KROSS, B. C.et al. The nitrate contamination of private well water in Iowa. American Journal of Public Health, v. 83, n.2, p. 270-272, 1993.

LIU, A.; MING, J.; ANKUMAH, R. O. Nitrate contamination in private wells in rural Alabama, United States. Science of the Total Environment, v. 346, p. 112-120, 2005.

LOPES, L. G.et al. Estudo do uso do solo e condições ambientais da Microbacia Hidrográfica do Córrego Rico. Fazu em Revista, v. 1, p. 16-24, 2008.

LUCENA, L. R. F.; ROSA FILHO, E. F.; BITTENCOURT, A. V. L. Características hidroquímicas do aquífero Barreiras no âmbito do setor oriental da Bacia do Rio Pirangi-RN. Revista Águas Subterrâneas, v. 18, p. 29-38, 2004.

MITCHELL, R. J.et al. Nitrate distributions and source identification in the AbbotsfordSumas Aquifer, northwestern Washington state. Journal of Environmental Quality, v. 32, p. 789-800, 2003.

RICHARDS, R.P.et al. Well water quality, well vulnerability, and agricultural contamination in the midwestern United States. Journal of Environmental Quality, v. 25, n. 3, p. 389-402, 1996.

SEADE. Fundação Sistema Estadual de Análise de Dados. Disponível: <http://www.seade.gov.br>. Acesso em: 12 maio 2009.

SILVA, M. A. S.; GRIEBELER, N. P.; BORGES, L. C. Uso de vinhaça e impactos nsa propriedades do solo e lençol freático. Revista Brasileira de Engenharia Agrícola e Ambiental, v. 11, n. 1, p. 108-114, 2007.

SQUILLACE, P. J.et al. pesticides, nitrate, and their mixtures in groundwater used for drinking water in the United States. Environmental Science and Technology, v.36, p.19231930, 2002. 
STATSOFT, Inc. (2004). STATISTICA (Data Analysis Software System), version 7. www.statsoft.com.

VARNIER, C.; HIRATA, R. Contaminação da água subterrânea por nitrato no Parque Ecológico do Tietê - São Paulo, Brasil. Revista Ấguas Subterrâneas, v. 16, p. 97-104, 2003.

WASSENAAR, L. I.; HENDRY, M. J.; HARRINGTON, N. Decadal geochemical and isotopic trends for nitrate in transboundary aquifer and implications for beneficial management practices. Environmental Science and Technology, v.40, n.15, p.4626-4632, 2006.

WILLIAMS, A. E.et al. Natural and anthropogenic nitrate contamination of groundwater in a rural community, California. Environmental Science and Technology, v. 32, n. 1, p. 32-39, 1998. 